NOTA CIENTÍFICA

\title{
MÉTODO DE DILUIÇÃO DO SOLO PARA ESTIMAR O POTENCIAL DE INÓCULO DE Plasmodiophora brassicae
}

\section{SOIL DILUTION METHOD FOR THE ESTIMATION THE INOCULUM POTENTIAL OF Plasmodiophora brassicae}

\author{
lonete HASSE ${ }^{1}$ \\ Louise Larissa MAY DE MIO² \\ Vismar da Costa LIMA NETO²
}

\begin{abstract}
RESUMO
Os produtores de brássicas da região Metropolitana de Curitiba-PR têm constatado danos severos em suas plantações em conseqüência da ocorrência da doença hérnia das crucíferas causada por Plasmodiophora brassicae. Nesta região há uma carência de dados do grau de infestação dos solos, desta forma o objetivo deste trabalho foi estabelecer uma metodologia para estimar os riscos de infecção de crucíferas por P.brassicae em dois solos com histórico da doença de duas áreas distintas de Colombo-PR (Boicininga e Serrinha). O experimento foi conduzido em casa-de-vegetação, utilizando a rúcula (Eruca sativa Mill) como planta hospedeira; esta foi semeada em vasos contendo solo infestado, e diluído (misturado com solo esterilizado) nas seguintes proporções: 1:1, 1:2, 1:4, 1:8, 1:16, 1:32. Após 45 dias do plantio, foram determinadas a massa aérea fresca (g), a incidência de galhas e a severidade da doença (notas). As plantas do solo de Boicininga apresentaram elevada severidade da doença até a diluição 1:32 enquanto que as plantas do solo de Serrinha apresentaram menor severidade da doença a partir da diluição 1:4. Não houve diferença significativa em nível de $5 \%$ da patogenicidade e severidade nas diluições do solo oriundo de Boicininga, PR. O solo oriundo de Serrinha apresentou um decréscimo nas variáveis incidência e severidade. O método de diluição mostrou-se uma ferramenta útil na avaliação dos riscos de infecção nos campos produtores de crucíferas por $P$. brassicae.
\end{abstract}

Palavras-chave: Hérnia das crucíferas; brássicas; infestação solo; Eruca sativa.

\begin{abstract}
The producers of brassicas in the Metropolitan region of Curitiba-PR have identified severe damage in their crops due to the disease club root caused by $P$. brassicae. In that region, there is lack of data concerning the degree of soil infestation. Therefore, the objective of this paper was to design a comparative methodology to quantify the risk of infection of the disease in two soils contaminated from two areas in Colombo-PR, (Boicininga and Serrinha). The experiment was conducted under greenhouse conditions using ruccula (Eruca sativa Mill) as the host plant: it was sowed in pots with infested soil and diluted (mixed with sterile soil) in the following proportions: 1:1, 1:2, 1:4, 1:8, 1:16, 1:32. Forty-five days after planting, aerial fresh matter, incidence and disease severity were determined. The soil in Boicininga presented disease severity up to 1:32 dilution, whereas the soil in Serrinha presented a decrease in disease severity from 1:4 dilutions onwards. There was no significant difference at $5 \%$ level between the treatments for the incidence and severity in dilutions with Boicininga soil. From Serrinha soil the plants presented a decrease in the variables incidence and severity. The dilution method was revealed as an important tool in the assessment of the potential of development of the disease, and can be recommended to distinguish inoculum potential of $P$. brassicae in crucifer's productions fields.

Key-words: clubboot, brassicas; Eruca sativa; soil infestation.
\end{abstract}

${ }^{1}$ Universidade Tecnológica Federal do Paraná, km 01, Caixa Postal 571, Bairro Fraron, 85503390, Pato Branco, PR, Fax: (41)3220-2500. E-mail: hasse@utfpr.edu.br. Autor para correspondência

${ }^{2}$ Departamento de Fitotecnia e Fitossanitarismo, UFPR, Rua dos Funcionários, 1540, 80035-050, Curitiba, PR, fax: (41)33505601 


\section{INTRODUÇÃO}

A hérnia das crucíferas (Plasmodiophora brassicae Woronim) tem distribuição mundial, tendo sido relatada por JAGGIAN et al. (1999) em cultivos de diferentes países dentre eles a Austrália, Nova Zelândia, Estados Unidos e Japão. No Brasil está presente nas regiões produtoras de brássicas, especialmente naquelas de clima úmido e de temperaturas entre 18 a $35^{\circ} \mathrm{C}, \mathrm{pH}$ abaixo de $7,0 \mathrm{e}$ em solos arenosos (MURAKAMI et al., 2000; ZAMBOLIM, 2001). Culturas instaladas em solos infestados têm produção severamente limitada sem o emprego de medidas drásticas de controle (TOKESHI e SALGADO,1980).

$\mathrm{Na}$ região Metropolitana de Curitiba-PR, vários trabalhos têm sido conduzidos na tentativa de minimizar os danos por essa doença, utilizando controle biológico, controle químico e avaliação de resistência e cultivares (LIMA et al., 1997; MAY DE MIO et al., 1997; MAY DE MIO; 2003; SCHUTA, 2003). Recentemente PAZ LIMA et al. (2004) verificaram a presença da doença em áreas cultivadas com rúcula (Eruca sativa Mill) no município de Quatro Barras-PR. Entretanto, são poucos os dados referentes ao número de áreas contaminadas, bem como sobre o grau de infestação. Dentre os poucos trabalhos publicados sobre a ocorrência da hérnia das crucíferas no Brasil (VIÉGAS e TEIXEIRA, 1943; CAFE FILHO e REIFSCHNEIDER, 1986; PAZ LIMA et al., 2004), não há conhecimento do grau de infestação dos solos.

Em outros países o potencial de inóculo pode ser estimado pela detecção de $P$. brassicae diretamente do solo por meio da extração dos esporos de resistência (DHINGRA e SINCLAIR 1994). Outra técnica de detecção da doença consiste em avaliar os sintomas no campo e coletar plantas hospedeiras doentes para extração e purificação de esporos (CASTLEBURY et al., 1994). Entretanto, as técnicas descritas acima não permitem avaliar o potencial de inóculo ativo da área. ROUXEL e CANDIOU (1988) considerando este fato trabalharam com a determinação de população de $P$. brassicae em solos relacionando número de esporos $\mathrm{g}^{-1}$ de solo com índices de doença, verificando relação linear entre nível de inóculo e doença. Entretanto, para avaliar o potencial de desenvolvimento da doença em solos naturalmente infestados não são relatados métodos específicos, considerando que dados de extração e contagem dos esporos de resistência são insuficientes para indicar a possibilidade e intensidade do surgimento da enfermidade em áreas de produção.

O presente trabalho objetivou testar o método de diluição do solo para estimar o risco de infecção de crucíferas em dois solos naturalmente infestado com $P$. brassicae.

\section{METODOLOGIA}

Os experimentos foram conduzidos em casa de vegetação da Universidade Federal do Paraná no Setor de Ciências Agrárias, Curitiba-PR no período de outubro a dezembro de 2003.

Os dois solos infestados naturalmente com Plasmodiophora brassicae foram coletados em áreas distintas do município de Colombo-PR (Boicininga e Serrinha), na região Metropolitana de Curitiba-PR. Dez amostras de cada área foram coletadas na profundidade de 0 a $20 \mathrm{~cm}$ e encaminhadas para os laboratórios de análise física e química da Universidade Federal do Paraná (LIMA, 2003).

O solo não infestado foi coletado no Setor de Ciências Agrárias da UFPR na área de compostagem em 2003 e foi esterilizado em forno a vapor por oito horas, com temperatura próxima de $90^{\circ} \mathrm{C}$.

Os tratamentos foram constituídos de solos naturalmente infestados e das diluições (mistura de solo estéril com infestado) nas diferentes proporções: $1: 1,1: 2,1: 4,1: 8,1: 16,1: 32$ as quais foram obtidos da seguinte forma: a diluição $1: 1$ foi constituída de $50 \%$ do solo naturalmente contaminado mais $50 \%$ de solo esterilizado; a diluição $1: 2$ recebeu $50 \%$ da diluição $1: 1$ e mais $50 \%$ de solo esterilizado; a diluição $1: 4$ recebeu $50 \%$ da diluição $1: 2$ mais $50 \%$ solo esterilizado; a diluição $1: 8$ recebeu $50 \%$ da diluição 1:4 mais $50 \%$ de solo esterilizado. A diluição 1:16 recebeu $50 \%$ da diluição $1: 8$ mais $50 \%$ de solo esterilizado. A diluição $1: 32$ recebeu $50 \%$ da diluição $1: 16$ mais $50 \%$ de solo esterilizado.

A fim de verificar a infestação do solo pelo patógeno utilizou-se a rúcula como planta teste. Três sementes foram semeadas diretamente em recipientes plásticos com capacidade de $300 \mathrm{~g}$ de solo e, após 10 dias, efetuou-se o desbaste deixando uma planta por vaso. A umidade foi mantida por regas diárias de aproximadamente $50 \mathrm{ml}$ de água por recipiente.

Após 45 dias do plantio, as plantas foram colhidas, lavadas e em seguida determinadas às variáveis: massa aérea fresca (g), incidência de galhas (presença e ausência de galhas) e índice de severidade de acordo com a escala de notas que varia de $\mathrm{A}=$ ausente a $\mathrm{C}=$ máxima, nota 3,5 a 4,0 (HASSE, 2005).

Os experimentos foram conduzidos em delineamento inteiramente casualizado, com seis repetições e sete tratamentos (solo naturalmente infestado e as diluições 1:1, 1:2, 1:4, 1:8, 1:16, 1:32). Para análise dos dados utilizou-se o software SASM - Agri Sistema realizando-se análise da variância e teste de comparação de médias (ALTHAUS et al., 2001). Considerando as concentrações do solo infestado, foram realizadas regressões polinomial e logarítmica entre as variáveis massa aérea fresca, número de plantas com galhas e severidade da doença. 
HASSE, I. et al. Método de diluição do solo para estimar...

\section{RESULTADOS E DISCUSSÃO}

Não foram observadas diferenças químicas importantes entre os dois solos, principalmente em relação ao $\mathrm{pH}$, teor de $\mathrm{Ca}, \mathrm{Mg}$ e $\mathrm{C}$ (dados não apresentados). Entretanto, o nível mais alto de fósforo no solo Serrinha pode ter possibilitado um maior desenvolvimento da massa aérea fresca nas primeiras diluições, quando comparados com o solo Boicininga, visto que em outros patossistemas geralmente teores maiores de fósforo propiciaram aumento na resistência e no vigor, bem como aceleraram a velocidade de maturação dos tecidos, encurtando o período de maior predisposição do hospedeiro (HUBER, 1989; MARSCHNER, 1986).

O solo Boicininga apresentou um teor de areia fina mais elevada o que segundo MURAKAMI et al. (2000) contribui para o surgimento da doença. Sendo que os mesmos autores verificaram um índice maior de severidade da doença em solo de textura arenosa, quando compararam dois solos de texturas diferentes. Por outro lado, essas pequenas diferenças, principalmente as relativas às características químicas dos solos em estudo, tornaram-se menos relevantes à medida que os tratamentos de diluição foram empregados (Tabela 1).

TABELA 1 - Efeito dos tratamentos sobre a massa aérea fresca de rúcula e sobre a incidência de Plasmodiophora brassicae em dois solos oriundos de Colombo-PR (Boicininga e Serrinha), dezembro de 2003.

\begin{tabular}{|c|c|c|c|c|}
\hline \multirow[t]{2}{*}{ Tratamentos } & \multicolumn{2}{|c|}{ Massa aérea fresca $(\mathrm{g})^{\star}$} & \multicolumn{2}{|c|}{$\mathrm{N}^{\circ}$ de plantas com galhas ${ }^{* *}$} \\
\hline & Boicininga & Serrinha & Boicininga & Serrinha \\
\hline Solo infestado & $1,12 b$ & 1,69 ns & $6 \mathrm{~ns}$ & $6 a$ \\
\hline Diluição 1:1 & $1,09 \mathrm{~b}$ & 1,58 & 6 & 6 a \\
\hline Diluição 1:2 & 2,30 a & 1,56 & 6 & 6 a \\
\hline Diluição 1:4 & 3,05 a & 2,04 & 6 & 6 a \\
\hline Diluição 1:8 & $2,84 a$ & 2,24 & 6 & $5 a b$ \\
\hline Diluição 1:16 & 4,05 a & 3,02 & 4 & $1 \mathrm{bc}$ \\
\hline Diluição 1:32 & 2,43 a & 3,86 & 6 & $2 c$ \\
\hline Médias & $2,41 \mathrm{~A}$ & $2,38 \mathrm{~A}$ & $5,7 \mathrm{~A}$ & $4,3 \mathrm{~A}$ \\
\hline CV.\% & 32,33 & 44,74 & 20,49 & 38,43 \\
\hline
\end{tabular}

À medida que o solo infestado foi sendo diluído e, por conseqüência, houve uma diminuição na concentração das unidades de propagação do patógeno, ocorreu uma redução significativa no número de plantas com a doença, principalmente nas diluições 1:16 e 1:32 no solo Serrinha (Tabela 1). Em relação à severidade, o solo de Boicininga (Figura 1) apresentou índice máximo da escala (notas 3,5 a 4) até a diluição 1:32, indicando novamente um maior riscos de infecção de crucíferas por $P$. brassicae nesse solo e que pode ser atribuído ao potencial de inóculo superior ao solo Serrinha. O mesmo foi observado por ROUXEL e CANDIOU (1988) determinando a população de $P$. brassicae em solos em número de esporos/g de solo, sendo testados as concentrações de $10^{2}$ a $10^{7}$ as quais propiciaram uma relação linear $(r=0,95)$ entre a concentração do inóculo e o desenvolvimento da doença. 
HASSE, I. et al. Método de diluição do solo para estimar...

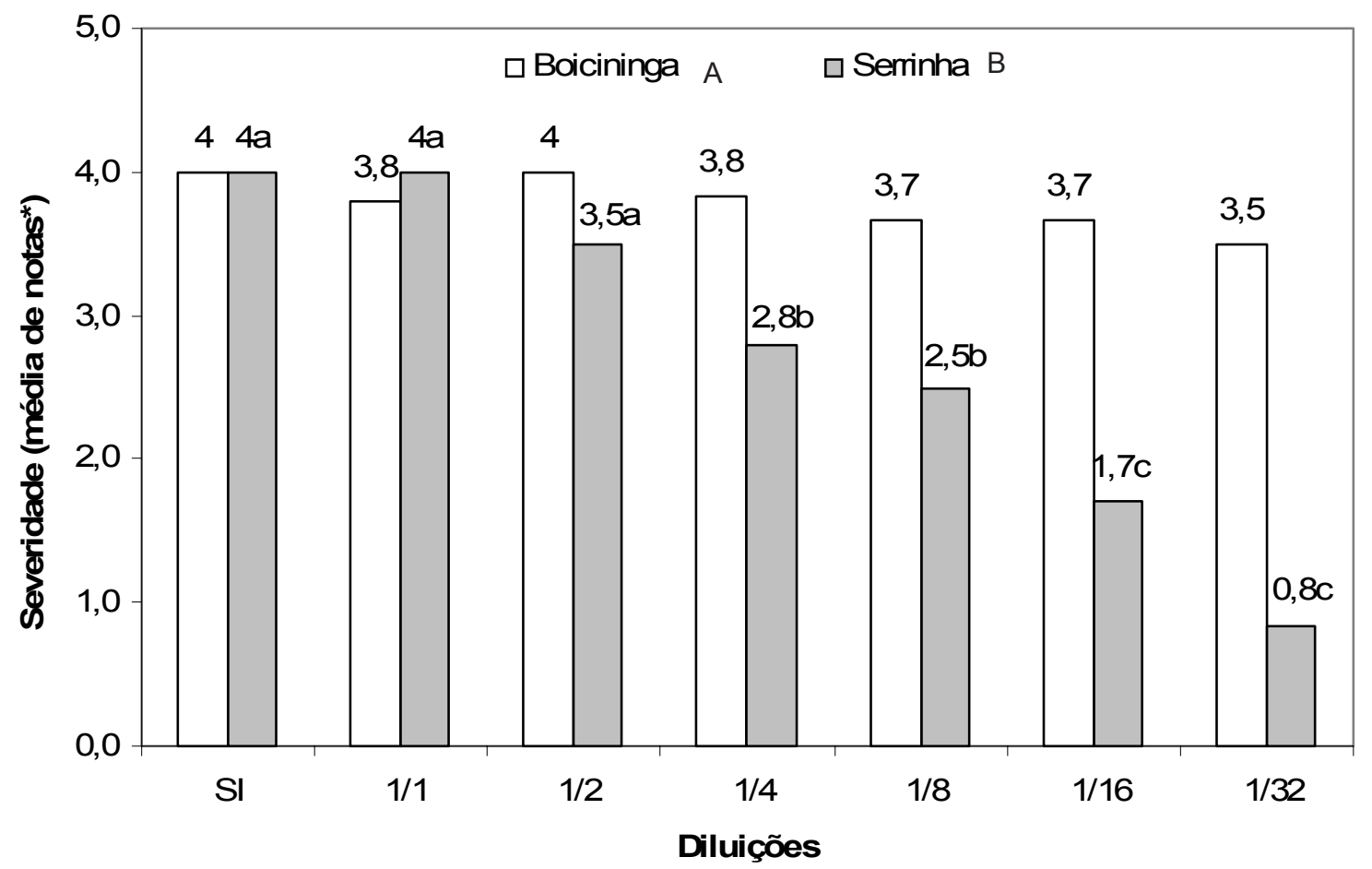

FIGURA 1 - Efeito dos tratamentos de diluição com dois tipos de solos (Boiciningans e Serrinha) sobre a severi dade da hérnia das crucíferas (P.brassicae). ( $\mathrm{SI}=$ solo infestado sem diluição, 1:1 a 1:32, proporções de diluição entre solo infestado e solo esterilizado). Média de seis repetições, seguidas da mesma letra minúscula não diferem estatisticamente (Scott-Knott $5 \%$ ). Letras maiúsculas comparam os solos. ns - severidade não significativa estatisticamente para o solo Boicininga. *escala de notas de 0 a 4, (HASSE, 2005).

No solo Serrinha (Figura 1) houve um decréscimo no índice de severidade a partir da diluição $1: 4$, indicando menor potencial de inóculo no solo comparado com o de Boicininga, pois o referido solo apresenta uma menor quantidade de esporos viáveis e, conseqüentemente, uma severidade menor (notas 0,1 a 2,0 ) nas últimas diluições (1:16 e 1:32).

Em relação à regressão (Figura $2 a$ e $2 b$ ) observa-se razão positiva para os valores de massa aérea fresca para os dois solos avaliados sendo explicado aproximadamente $70 \%$ da perda de matéria seca em detrimento do potencial de inóculo do solo, seguindo as diluições e número de plantas com galhas e severidade. O número de plantas com galhas não teve relação direta com a diluição do solo Boicininga (Figura 2c), pois este estava com um potencial de inóculo muito alto e, praticamente todas as plantas evidenciavam pelo menos algum sintoma da doença totalizando na maioria das vezes $100 \%$ de incidência. Para o outro solo (Figura 2d) (de menor potencial de inóculo) esta relação foi observada com $r=0,74$ na regressão logarítmica. Na Figura 2 e e $2 f$ observou-se relação entre as diluições e a severidade para ambos os solos por ser esta uma variável mais discriminatória, atingindo $r=0,95$ no solo Serrinha. 
HASSE, I. et al. Método de diluição do solo para estimar...

Massa aérea fresca $(g)$

Boicininga

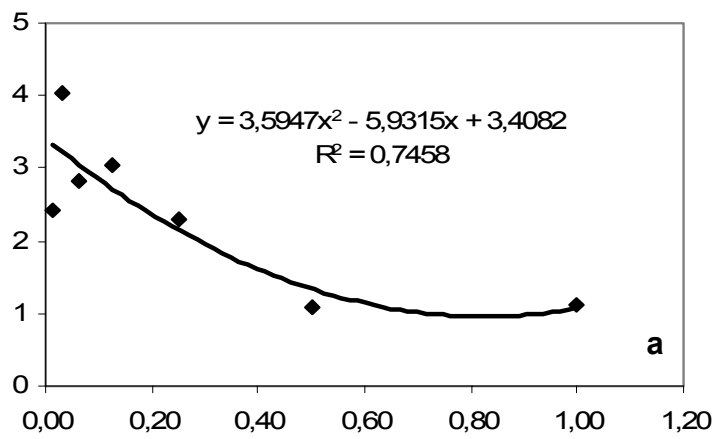

Serrinha

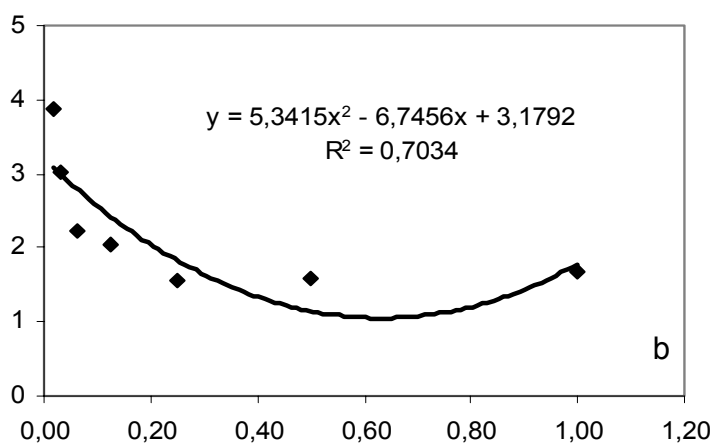

Número de plantas com galhas
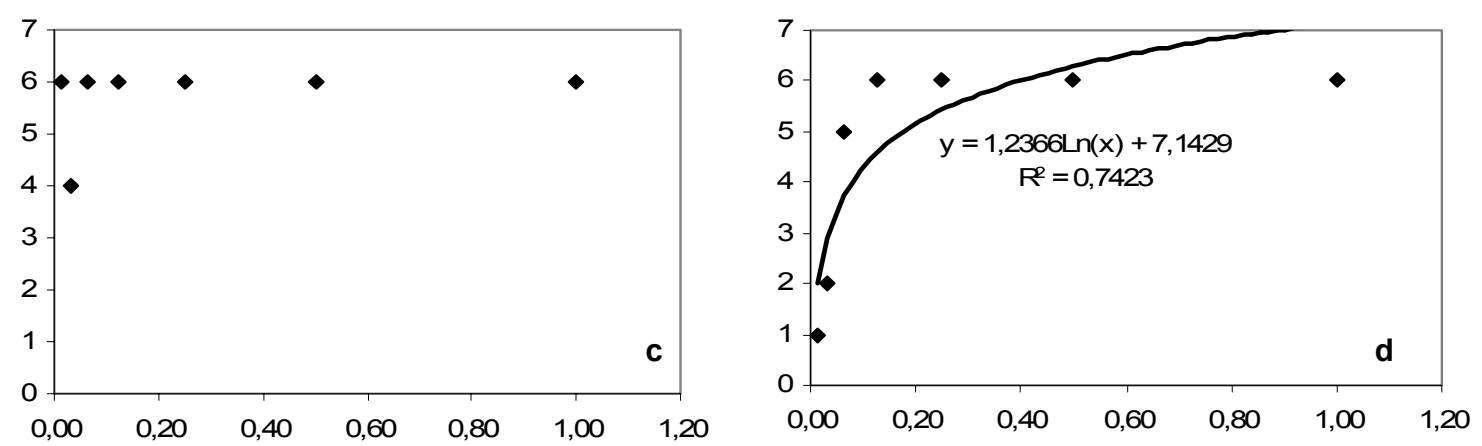

Severidade (média, em escala de notas)
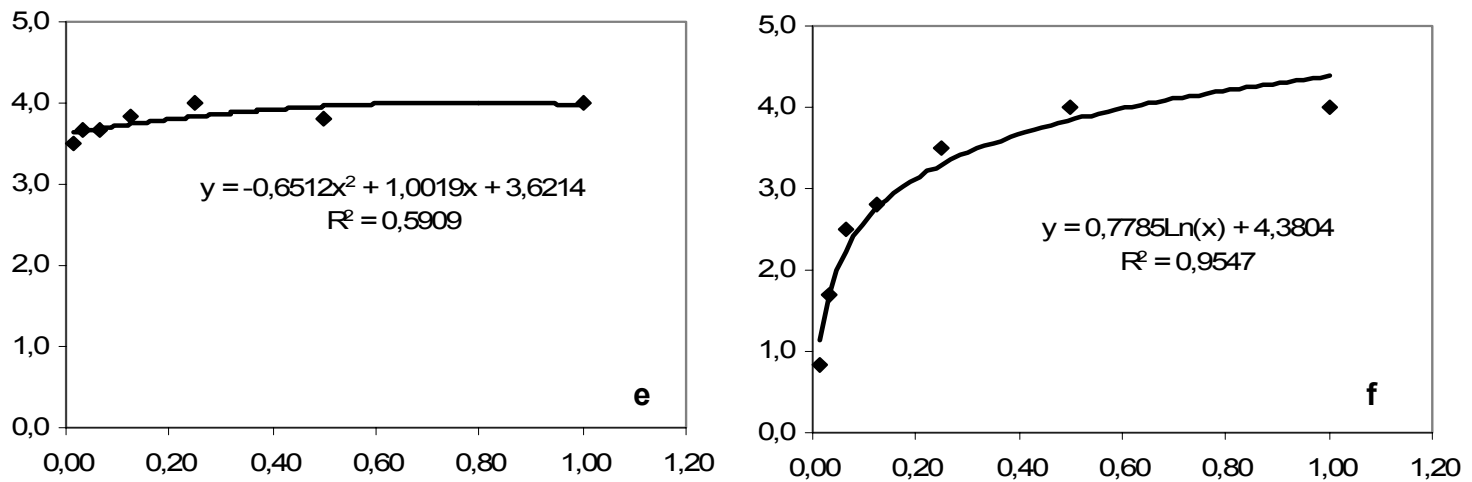

FIGURA 2 - Regressão entre massa aérea fresca de rúcula $(a, b)$, número de plantas com galhas (c,d) e severidade de Plasmodiophora brassicae em rúcula $(e, f)$ em relação a diferentes diluições de solo infestados, (sem diluição=1,1:1=0,5, 1:2=0,25, 1:4=0,13, 1:8=0,063, 1:16=0,031, 1:32= $0,016)$. Para $a, b, e$ a regressão foi polinomial e para $d, f$ foi logarítmica. 
HASSE, I. et al. Método de diluição do solo para estimar...

MAY-DE MIO et al. (1997) testando quatro níveis de inóculo de $P$. brassicae (de 2, 5, 10 a $20 \mathrm{~g}$ vaso $^{-1}$ ), observaram que mesmo na menor concentração é alto o índice de galhas nas plantas. SCHUTA (2003) observou que aumentando a concentração de inóculo para níveis mais elevados (5. $10^{7}$ esporos $\mathrm{ml}^{-1}$ por vaso de $1,5 \mathrm{~kg}$ de solo) a severidade da doença progrediu mesmo para níveis mais altos de $\mathrm{pH}(7,3)$. Em trabalho de ROUXEL e CANDIOU (1988) com couve chinesa o nível de inóculo de $5.10^{3}$ esporos $\mathrm{g}^{-1}$ de solo foi capaz de provocar índice de doença de $50 \%$, e também relatou que existem diferenças entre os solos que influenciam na capacidade de expressar a doença com equivalentes concentrações do patógeno.

O método de diluição de solo mostrou-se útil para avaliar riscos de infecção de crucíferas por $P$. brassicae em solos infestados, considerando que dados de extração e contagem dos esporos de resistência são insuficientes para indicar o potencial e intensidade do surgimento da hérnia. Além disso, a técnica pode ser útil em levantamentos de distribuição espacial da doença, classificando em notas de potencial de inóculo além de apenas presença e ausência da doença.

O método de diluição de solos para avaliar os riscos de infecção de crucíferas por $P$. brassicae pode ser útil na tomada de decisões de local para plantio de crucíferas na propriedade e também para programar o controle ou manejo da doença. Para o manejo é importante considerar que a calagem, uma das práticas de controle mais utilizadas, não exerce um controle efetivo sobre o ataque do patógeno quando a concentração de inóculo é elevada. (MAY DE MIO, 1997; SCHUTA, 2003).

\section{CONCLUSÕES}

O método de diluição de solo possibilita informar o risco de infecção de crucíferas por Plasmodiophora brassicae.

O solo de Boicininga tem maior infestação com P. brassicae comparado ao solo Serrinha.

\section{REFERÊNCIAS}

1. ALTHAUS, R.A.; CANTERI, M.G.; GIGLIOTI, E.A. Tecnologia da informação aplicada ao agronegócio e ciências ambientais: sistema para análise e separação de médias pelos métodos de Duncan, Tukey e Scott-Knott. In: ENCONTRO ANUAL DE INICIAÇÃO CIENTÍ́FICA, 10., 2001, Ponta Grossa. Anais. Ponta Grossa: Universidade Estadual de Ponta Grossa, 2001. p. 280-281.

2. CAFÉ FILHO, A.; REIFSCHNEIDER, F.J.B. Ocorrência de Plasmodiophora brassicae no Distrito Federal. Horticultura Brasileira, v. 4, n. 1, p.35-36, 1986.

3. CASTLEBURY, L.A; MADDOX, J.V; GLAWE, D.A.A technique for the extraction and purification of viable Plasmodiophora brassicae resting spores from host root tissue. Mycologia, v. 86, n. 3, p. 458-460, 1994.

4. DHINGRA, O; SINCLAIR, J. Basic plant pathology methods. 2. ed. London: Lewis Publishers, 1994. p.92-93.

5. HASSE, I. Quantificação de Plasmodiophora brassicae e uso de plantas medicinais para controle da doença. Curitiba, 2005. 96 f. Tese (Doutorado em Agronomia) - Curso de Pós-graduação em Produção Vegatal, Setor de Ciências Agrárias, Universidade Federal do Paraná.

6. HUBER, D.M. The role of nutrition in take-all disease of wheat and other small grains. In: ENGELHARD, A.W. Soilborne plant pathogens: Management of diseases with macro- and micronutrients. St Paul: APS Press, 1989. p. 46-67.

7. LIMA, M.R. (Ed.). Manual de diagnóstico da fertilidade e manejo dos solos agrícolas. Curitiba: Universidade Federal do Paraná, Departamento de Solos e Engenharia Agrícola, 2003. 67 p.

8. LIMA, M.L.R.Z.C.; MAY-DE MIO, L.L.; LOLIS, R. Controle físico e biológico da hérnia das crucíferas (Plasmodiophora brassicae Wor) na Região Metropolitana de Curitiba-PR. Revista do Setor de Ciências Agrárias, v. 16, n. 1-2, p. 8387, 1997.

9. MARCHNER, H. Mineral nutrition of higher plants. New York: Academic Press, 1986. 675 p.

10. MAY DE MIO, L.L.; SILVA, J.; LIMA, M.L.R.Z.C. Avaliação de diferentes formas de controle de Plasmodiophora brassicae em couve-chinesa em condições de casa de vegetação. Revista do Setor de Ciências Agrárias, v. 16, n. 1-2, p. 9-14, 1997.

11. MAY DE MIO, L.L. Resistência de cultivares de brássicas à hérnia das crucíferas. In: CONGRESSO BRASILEIRO DE FITOPATOLOGIA, 36. Uberlândia, 2003. Anais. Uberlândia, 2003. 1 CD-ROM.

12. MURAKAMI, H.; TSUSHIMA, S.; SHISHIDO, Y. Soil suppressiveness to clubroot disease of Chinese cabbage caused by Plasmodiophora brassicae. Soil Biology \& Biochemistry, v. 32, p. 1637-1642, 2000.

13. ROUXEL, F.; CANDIOU, M. Estimation dês populations de Plasmodiophora brassicae Wor. Dans lês sols. Agronomie, v. 8, n. 7, p.653-656, 1988.

14. PAZ LIMA, M; CAFÉ-FILHO, A.C.; NOGUEIRA, N.L.; ROSSI, M.L.; SCHUTA, L.R. First report of clubroot of Eruca sativa caused by Plasmodiophora brassicae in Brazil. Plant Disease, v. 88, p. 573, 2004.

15. SCHUTA, L. R. Boro, nitrogênio, concentração de inóculo e pH no controle da Plasmodiophora brassicae. Curitiba, 2003. 97 f. Tese (Doutorado em Agronomia) - Curso de Pós-graduação em Produção Vegetal, Setor de Ciências Agrárias, Universidade Federal do Paraná

16. TOKESHI, H.; SALGADO, L.C. Doenças das crucíferas. In: GALLI, F. Manual de fitopatologia: doenças de plantas cultivadas. São Paulo: Agronômica Ceres, 1980. p. 236-250.

17. VIÉGAS, A.P.; TEIXEIRA, A.R. Alguns fungos do Brasil (Phycomycetos). Bragantia, v. 3, n. 8, p. 23-269, 1943.

18. ZAMBOLIM, L. Manejo integrado fitossanidade: cultivo protegido, pivô central e plantio direto. Viçosa: Universidade Federal de Viçosa, 2001.722 p.

Recebido em 09/04/2007

Aceito em 06/08/2007 